\title{
Properties of amorphous silicon thin films grown in square wave modulated silane rf discharges
}

\author{
J. L. Andújar, E. Bertran, A. Canillas, J. Campmany, J. Serra, and C. Roch \\ Departament de Fisica Aplicada i Electrònica, Universitat de Barcelona, Av. Diagonal 647, \\ E08028-Barcelona, Spain
}

\begin{abstract}
A. Lloret
Laboratoire de Physique des Interfaces et des Couches Minces, (UPR 0258 du C.N.R.S.), Ecole Polytechnique, F91128-Palaiseau Cedex, France
\end{abstract}

(Received 6 June 1991; accepted for publication 21 October 1991)

\begin{abstract}
Hydrogenated amorphous silicon $(a-\mathrm{Si}: \mathrm{H})$ thin films have been obtained from pure $\mathrm{SiH}_{4} \mathrm{rf}$ discharges by using the square wave modulation (SQWM) method. Film properties have been studied by means of spectroellipsometry, thermal desorption spectrometry, photothermal deflection spectroscopy and electrical conductivity measurements, as a function of the modulation frequency of the rf power amplitude $(0.2-4000 \mathrm{~Hz})$. The films deposited at frequencies about $1 \mathrm{kHz}$ show the best structural and optoelectronic characteristics. Based upon the experimental results, a qualitative model is presented, which points up the importance of plasma negative ions in the deposition of $a$-Si:H from SQWM If discharges through their influence on powder particle formation.
\end{abstract}

In spite of extensive research on the preparation of hydrogenated amorphous silicon ( $a-\mathrm{Si}: \mathrm{H})$ thin films by rf glow discharge decomposition of $\mathrm{SiH}_{4}$, there have so far been few works devoted to the effects of rf power amplitude square-wave modulation (SQWM). ${ }^{1-8}$ Experiments concerning $\mathrm{rf}$ discharges in $\mathrm{SiH}_{4}-\mathrm{He}$ mixtures at modulation frequencies, $f_{\text {mod }}$, in the acoustic range, ${ }^{1-7}$ have shown that the use of the SQWM technique increases the deposition rate and reduces the powder generation in the plasma volume, in comparison with the standard continuous wave (cw) method. In a previous paper, ${ }^{8}$ we reported an ellipsometric study of the effects of SQWM in pure $\mathrm{SiH}_{4} \mathrm{rf}$ discharges on the growth of $a-\mathrm{Si}: \mathrm{H}$ thin films. The main results of this study were an enhancement of the deposition rate with the increase of $f_{\text {mod, }}$ more marked at high $\mathrm{rf}$ power, and an important influence of modulation on the film optical quality depending on the rf power level and $f_{\text {mod }}$. These effects were discussed in terms of powder particles and negative ions, which play an important role in the discharge kinetics ${ }^{9}$ and might account for the differences observed between SQWM and cw discharges. The aim of this paper is to present new experimental results on the preparation of $a-\mathrm{Si}: \mathrm{H}$ thin films from SQWM $\mathrm{SiH}_{4}$ if discharges. In particular, the effects of SQWM on the material properties have been studied by means of several film characterization techniques, such as spectroscopic phase modulated ellipsometry (SPME), hydrogen thermal desorption spectrometry (TDS), photothermal deflection spectroscopy (PDS), and electrical conductivity measurements.

The $a$-Si:H samples were prepared in a confined plasma parallel electrode reactor provided with a computer-controlled gas-supply and pumping system ${ }^{10,11}$ and equipped with a fast spectroscopic phase modulated ellipsometer. ${ }^{12}$ Films about $1 \mu \mathrm{m}$ thick were deposited onto $c$-Si wafers, fused silica and Corning 7059 glass substrates placed on the grounded clcetrode at $300^{\circ} \mathrm{C}$. The output of the rf source $(13.56 \mathrm{MHz})$ was square wave modulated (100\% modulation depth and $75 \%$ duty cycle) in the $f_{\text {mod }}$ range $0.2-4000 \mathrm{~Hz}$ by means of a function generator, and the mean $\mathrm{rf}$ power density supplied to the discharges was set at $150 \mathrm{~mW} / \mathrm{cm}^{2}$. Other deposition conditions were 30 sccm of pure $\mathrm{SiH}_{4}$ gas flow rate and $30 \mathrm{~Pa}$ of pressure. The deposition rate of the films ranged from 0.8 to $1.1 \mathrm{~nm} / \mathrm{s}$ depending on $f_{\text {mod. }}{ }^{8}$

The complex pseudodielectric function, $\langle\epsilon\rangle=\left\langle\epsilon_{1}\right\rangle$ $-i\left\langle\epsilon_{2}\right\rangle$, of the films was measured in the $1.5-4.5 \mathrm{eV}$ range by ex situ SPME at room temperature. Figure 1 shows the $f_{\text {mod }}$ dependence of the maximum value of $\left\langle\epsilon_{2}\right\rangle,\left\langle\epsilon_{2}\right\rangle_{\max }$, which is related to the Si-Si bond packing density and also to the surface roughness and oxidation..$^{13}$ As previously reported, ${ }^{8}\left\langle\epsilon_{2}\right\rangle_{\max }$ first decreases with the increase in $f_{\bmod }$ from $\mathrm{cw}$ to $2 \mathrm{~Hz}$, and then rises until to values comparable to that of $\mathrm{cw}$ for $f_{\text {mod }} \geqslant 40 \mathrm{~Hz}$. The hydrogen thermal evolution spectra of the samples were obtained from TDS experiments performed at a temperature rate of $20^{\circ} \mathrm{C} / \mathrm{min}$ up to $800^{\circ} \mathrm{C}$. The spectra show an evolution peak centered at $565 \pm 15^{\circ} \mathrm{C}$ and a shoulder at lower temperatures. The high-temperature side of the peak was fitted to a Gaussian curve, and the fraction of the extra hydrogen evolved at low temperature (LTH) was estimated by subtracting the Gaussian area from the total integrated evolution. The LTH fraction as a function of $f_{\text {mod }}$ is also shown in Fig. 1, where an inverse relation between the LTH and $\left\langle\epsilon_{2}\right\rangle_{\max }$ dependences is observed, suggesting a modification of film microstructure induced by plasma modulation. In order to obtain further insight into these microstructural changes, the $\langle\epsilon\rangle$ spectra of films grown at different $f_{\text {mod }}$ were analyzed by applying the Bruggeman effective medium approximation and assuming a multilayer model,${ }^{14}$ composed of a surface roughness layer and a bulk material constituted by voids and dense $a$-Si:H $\left(\left\langle\epsilon_{2}\right\rangle_{\max }=28.8\right.$ at 3.74 $\mathrm{eV}$ ). From this analysis, the bulk void fraction, $F_{v}$, and the surface roughness, $R_{s}$, of the films were calculated includ- 


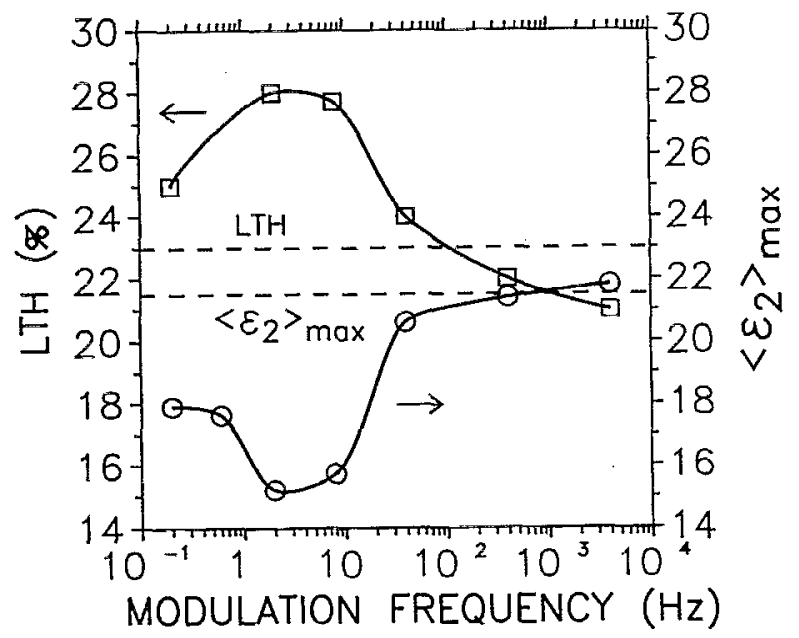

FIG. 1. Maximum of the imaginary part of pseudodielectric function $\left(\epsilon_{2 \max }\right)$ and the fraction of extra hydrogen evolved at low temperature (LTH), as a function of modulation frequency. The dashed lines denote the continuous wave $(\mathrm{cw})$ values.

ing in the $R_{s}$ values the contribution of a native oxide overlay thinner than $1 \mathrm{~nm}$. Figure 2 shows their dependences on $f_{\text {mod. }}$. Both parameters reach a maximum at $f_{\text {mod }}=2 \mathrm{~Hz}$ and show values close to those of cw for $f_{\text {mod }}>40 \mathrm{~Hz}$. These results are in agreement with in situ real time ellipsometric data previously reported. ${ }^{8}$

PDS measurements were carried out to obtain the optical absorption spectrum of the films in the $0.9-2 \mathrm{eV}$ range. From that, the Urbach edge parameter, $E_{o}$, was determined and the defect density, $N_{s}$, was calculated by integrating the subgap optical absorption excess. ${ }^{15}$ The $f_{\text {mod }}$ dependences of $E_{o}$ and $N_{s}$ plotted in Fig. 3, show that the subgap absorption and the film structural disorder, reflected in the $E_{o}$ parameter, ${ }^{16}$ are also affected by SQWM.

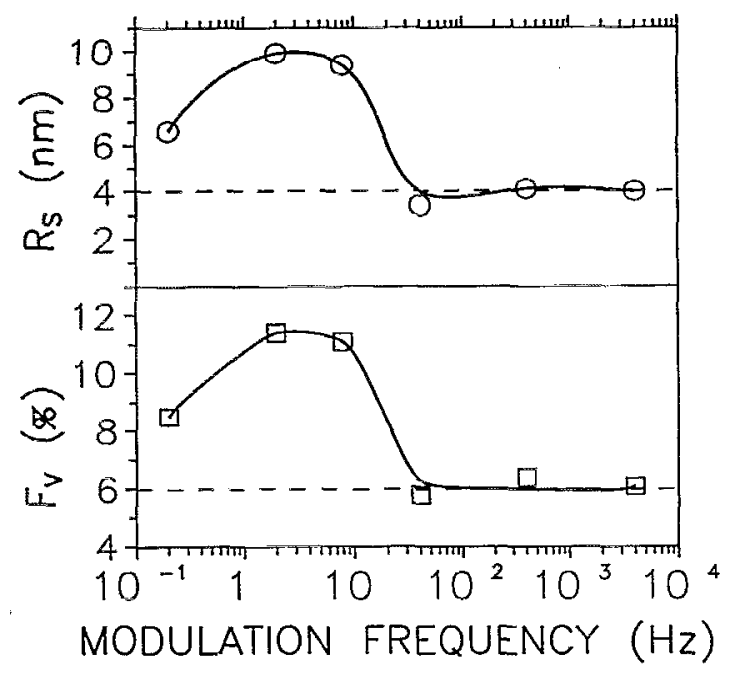

FIG. 2. Modulation frequency dependences of the surface roughness $\left(R_{s}\right)$ and the bulk void fraction $\left(F_{v}\right)$ parameters obtained from the spectroellipsometric analysis data. The $\mathrm{cw}$ parameters are represented by dashed lines.

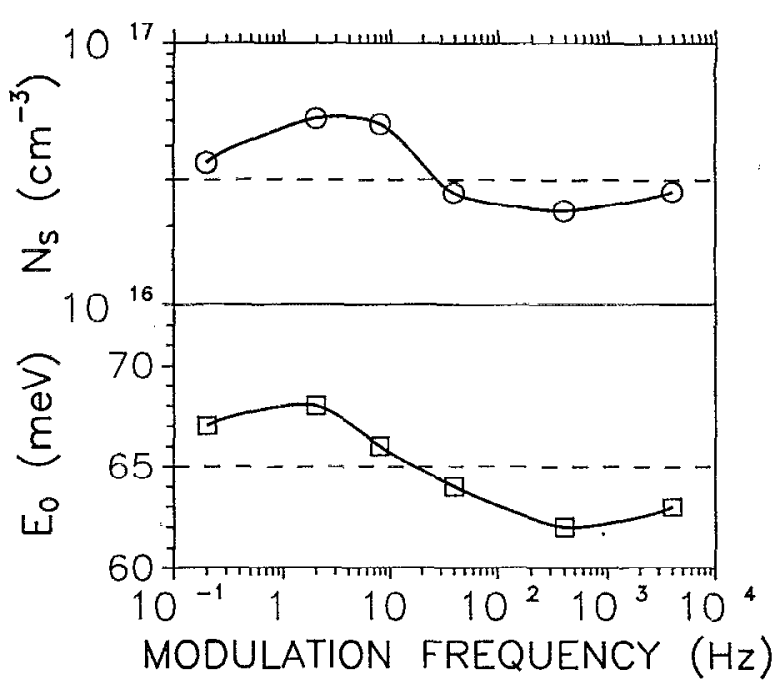

FIG. 3. Dependences of the subgap defect density $\left(N_{s}\right)$ and the Urbach parameter $\left(E_{0}\right)$ determined by PDS measurements, on the modulation frequency. The dashed lines represent the values corresponding to $\mathrm{cw}$ discharges.

Modulating at low $f_{\text {mod }}$ leads to an increase in $N_{s}$ and $E_{o}$, whereas the films grown at $f_{\text {mod }} \geqslant 40 \mathrm{~Hz}$ have lower $E_{o}$ and $N_{s}$ values than those corresponding to cw discharges. Electrical conductivity measurements were made under both dark and light conditions, using coplanar $\mathrm{Ni}$ - $\mathrm{Cr}$ electrode geometry. Dark conductivity, $\sigma_{d}$, was measured in the range $300-450 \mathrm{~K}$, whereas photoconductivity, $\sigma_{\mathrm{ph}}$, measurements were performed at $300 \mathrm{~K}$ with monochromatic light (602-nm wavelength, $3.3-\mathrm{mW} / \mathrm{cm}^{2}$ intensity). In addition, from the Arrhenius plot of the $\sigma_{d}$-temperature dependence, the activation energy, $E_{a}$, and the prefactor of $\sigma_{d}, \sigma_{o}$, were obtained. Table I summarizes the electrical parameters of films grown at different $f_{\text {mod }}$. Although the electrical properties of the SQWM samples are rather similar to those of the $\mathrm{cw}$ sample, at $f_{\text {mod }}=2 \mathrm{~Hz}$ the electrical parameters have slightly lower values than those corresponding to the other $f_{\text {mod }}$.

These results support our reported discussion about SQWM effects, based on a qualitative model that takes into account the importance of plasma negative ions. ${ }^{8}$ Primary negative ions are initially created in the silane discharge through electron attachment processes involving silane dissociation products. ${ }^{17} \mathrm{In} \mathrm{cw}$ discharges, negative species are confined by the plasma sheath potential, and because of their long residence time, can strongly polymerize in ionmolecule reactions, ${ }^{18}$ leading to the formation of powder

TABLE I. Electrical parameters of SQWM and cw samples.

\begin{tabular}{ccccc}
\hline \hline $\begin{array}{c}f_{\text {mod }} \\
(\mathbf{H z})\end{array}$ & $\begin{array}{c}\sigma_{d}(300 \mathrm{~K}) \\
\left(10^{-11} \mathrm{~S} / \mathrm{cm}\right)\end{array}$ & $\begin{array}{c}E_{a} \\
(\mathrm{eV})\end{array}$ & $\begin{array}{c}\sigma_{o} \\
\left(10^{3} \mathrm{~S} / \mathrm{cm}\right)\end{array}$ & $\begin{array}{c}\sigma_{\mathrm{ph}}(300 \mathrm{~K}) \\
\left(10^{-6} \mathrm{~S} / \mathrm{cm}\right)\end{array}$ \\
\hline $\mathrm{cw}$ & 2.8 & 0.84 & 2.1 & 0.93 \\
0.2 & 2.5 & 0.84 & 2.0 & 1.5 \\
2 & 1.6 & 0.82 & 0.83 & 0.35 \\
400 & 3.0 & 0.84 & 2.5 & 1.6 \\
\hline
\end{tabular}


particles. In contrast, in SQWM discharges, these negative species are allowed to reach the substrates each time the $\mathrm{rf}$ power is switched off. In addition, the degree of polymerization and so the size and the density of macroscopic particles depend on the time for which the discharge is on. At very low $f_{\text {mod }}$ this time can be long enough to allow the maximum size of particles, just like in $\mathrm{cw}$ discharges.

As the $f_{\text {mod }}$ is increased, the rate of polymerized ions and particles reaching the film during the rf power-off periods also increases. This explains why at $f_{\text {mod }}=2 \mathrm{~Hz}$, when the powder appearance is more visible, all the characteristics studied show an extreme behavior: higher porosity and surface roughness, larger fraction of hydrogen evolved at low temperature, higher subgap defect density, and worse electrical properties.

Nevertheless, at higher $f_{\text {mod }}(>40 \mathrm{~Hz})$, the available rf power-on time for particle size growth is reduced and can even become shorter than the time required for powder formation. In this case, the contribution of monomers to deposition during the afterglow periods will be more important. Moreover, as the largest primary attachment production in silane plasma corresponds to the $\mathrm{SiH}_{3}^{-}$ions and since the $\mathrm{SiH}_{3}$ radical has a longer lifetime than other radicals, at these $f_{\text {mod }}$, the films grow with an enhanced $\mathrm{SiH}_{3}$ monomer contribution. These considerations may account for the observed improvement, in particular at $f_{\text {mod }}$ about $1 \mathrm{kHz}$, of the $a-\mathrm{Si}: \mathrm{H}$ characteristics, namely, the recovering of the cw values of roughness and porosity and the decrease in the PDS and LTH parameters as compared to cw conditions.

At $f_{\text {mod }}=4 \mathrm{kHz}$ the PDS data seem to point to a slight decay of $a-\mathrm{Si}: \mathrm{H}$ optoelectronic quality, as might be expected, since the contribution to the film growth of shorter lifetime monomers, such as $\mathrm{SiH}_{2}$ and $\mathrm{SiH}$, would become more significant in the afterglows as the $f_{\text {mod }}$ is increased. Finally, it is interesting to note that for $f_{\text {mod }}>400 \mathrm{~Hz}$ the LTH values of SQWM films are lower than those shown by $\mathrm{cw}$ films, suggesting a different material stability behavior which is generally related to weak $\mathrm{Si}-\mathrm{H}$ bonds. ${ }^{19}$

In summary, the SQWM technique create new per- spectives to increase the $a-\mathrm{Si}: \mathrm{H}$ deposition rate with a reduced powder formation, and to obtain a material that can have structural and optoelectronic properties similar to or even better than that produced in $\mathrm{cw}$ plasmas.

We thank Professor J. L. Morenza for encouragement and Dr. J. Kasaneva for his help in the electrical measurements. This work was partially supported by the CICYT of Spain (Project MAT90-955) and the Acciones Integradas Hispano-Francesas no. 176 and no. 209 (1989-1990).

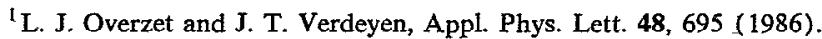

${ }^{2}$ L. J. Overzet, J. T. Verdeyen, R. M. Roth, and F. F. Carasco, Mater. Res. Soc. Proc. 98, 321 (1987).

${ }^{3}$ M. Shiratani, Y. Kubo, I. Ogawa, S. Matsuo, H. Makino, S. Ogi, and Y. Watanabe, Proc. Jpn. Sym. Plasma Chem. 1, 145 (1988).

${ }^{4}$ Y. Watanabe, M. Shiratani, Y. Kubo, I. Ogawa, and S. Ogi, Appl. Phys. Lett. 53, 1263 (1988).

${ }^{5}$ Y. Watanabe, M. Shiratani, S. Matsuo, and H. Makino, Proceedings of the 9th International Symposium on Plasma Chemistry, edited by $\mathrm{R}$. d'Agostino (University of Bari, Pugnochiuso, Italy, 1989), Vol. III, p. 1329.

${ }^{6}$ J. T. Verdeyen, J. Beberman, and L. J. Overzet, J. Vac. Sci. Technol. A 8, 1851 (1990).

${ }^{7}$ Y. Watanabe, M. Shiratani, and H. Makino, Appl. Phys. Lett. 57, 1616 (1990).

${ }^{8}$ A. Lloret, E. Bertran, J. L. Andújar, A. Canillas, and J. L. Morenza, J. Appl. Phys. 69, 632, (1991).

${ }^{9}$ F. Tochikubo, A. Suzuki, S. Kakuta, Y. Terazono, and T. Makabe, J. Appl. Phys. 68, 5532 (1990).

${ }^{10}$ J. L. Andújar, E. Bertran, A. Canillas, J. Esteve, J. Andreu, and J. L. Morenza, Vacuum 39, 795 (1989).

${ }^{11} \mathrm{~J}$. L. Andújar, E. Bertran, A. Canillas, C. Roch, and J. L. Morenza, J. Vac. Sci. Technol. A 9, 2216 (1991).

${ }^{12}$ A. Canillas, E. Bertran, J. L. Andújar, and J. L. Morenza, Vacuum 39, 785 (1989).

${ }^{13}$ R. W. Collins, in Amorphous Silicon and Related Materials, edited by H. Fritzsche (World Scientific, Singapore, 1988), Vol. B, p. 1003.

${ }^{14}$ D. E. Aspnes, J. B. Theeten, and F. Hottier, Phys. Rev. B 20, 3292 (1979).

${ }^{15}$ N. M. Amer and W. B. Jackson, in Hydrogenated Amorphous Silicon, edited by J. I. Pankove (Academic, Orlando, 1984), Part B, p. 83.

${ }^{16}$ G. D. Cody, T. Tiedje, B. Abeles, B. Brooks, and Y. Goldstein, Phys. Rev. Lett. 47, 1480 (1981).

${ }^{17}$ C. B. Fledderman, J. H. Beberman, and J. T. Verdeyen, J. Appl. Phys. 58, 1344 (1985).

${ }^{18}$ J. Perrin, A. Lloret, G. de Rosny, and J. P. M. Schmitt, Int. J. Mass Spec. Ion Process 57, 249 (1984)

${ }^{19}$ R. A. Street and K. Winer, Phys. Rev. B 40, 6236 (1989). 